\title{
ATIVIDADES COMPLEMENTARES CURRICULARES EM CONTRATURNO ESCOLAR NO ESTADO DO PARANÁ: um estudo do macrocampo esporte e lazer
}

\author{
Andréia Paula Baseil \\ Eduard Angelo Bendrath² \\ Pedro Henrique Iglesiaz Menegaldo3
}

\section{RESUMO}

O objetivo deste estudo foi realizar um levantamento sistemático das atividades complementares curriculares em contraturno escolar no macrocampo esporte e lazer desenvolvidas nas escolas públicas estaduais do Paraná. As informações cadastrais das escolas $(\mathrm{N}=372)$ dos dezenove municípios caracterizados como de grande porte disponíveis na plataforma DataEscolaBrasil (MEC), foram analisadas com base na estatística descritiva utilizando-se o software SPSS versão 20.0. Os resultados apontam que cinco projetos de atividades complementares concentram 40,5\% das ações nos 9 macrocampos previstos. Dentre os projetos executados aproximadamente $1 / 3$ estão vinculados ao macrocampo esporte e lazer $(35,4 \%)$. Neste macrocampo $64,9 \%$ dos projetos estão concentrados em 5 modalidades, apontando uma tendência a padronização das ações e a prevalência do esporte em detrimento das demais atividades de lazer. Conclui-se que as atividades complementares curriculares em contraturno reforçam ações em prol da educação integral e o macrocampo analisado apresenta grande potencial na ampliação das oportunidades de aprendizagem dos alunos.

Palavras-chave: Políticas Educacionais. Educação Integral. Atividades Complementares Curriculares em Contraturno. Esporte e Lazer.

1 Mestre em Educação. Professora da Universidade Estadual de Maringá (UEM). Maringá/Paraná, Brasil. E-mail: andreiabasei@yahoo.com.br

2 Doutor em Educação. Professor da Universidade Estadual de Maringá (UEM). Maringá/Paraná, Brasil. E-mail: bendrath@gmail.com

3 Graduado em Educação Física. Universidade Estadual de Maringá (UEM). Maringá/Paraná, Brasil. E-mail: pedromenegaldo@hotmail.com 


\title{
CURRICULAR ACTIVITIES COMPLEMENT IN EXTRA-CURRICULAR SHIFT IN SCHOOLS OF PARANÁ STATE: a study in field sports and leisure
}

\begin{abstract}
The aim of this study was to conduct a systematic survey of the curricular activities complement in extra-curricular shift in schools in field sports and leisure developed in public schools in Paraná state. The registration information of schools $(N=372)$ of the nineteen of large cities available in DataEscolaBrasil platform (MEC), were analyzed using descriptive statistics using SPSS software version 20.0. The results show that five complementary project activities concentrated $40.5 \%$ of the shares in 9 fields provided. Among the projects executed approximately $1 / 3$ are linked to sports and leisure $(35.4 \%)$. In this field $64.9 \%$ of projects are concentrated in 5 modes, indicating a tendency to standardize the actions and the prevalence of sport to the detriment of other leisure activities. It was concluded that curricular activities complement in extra-curricular shift reinforce actions in support of comprehensive education and area analysis has great potential in expanding learning opportunities for students.
\end{abstract}

Keywords: Educational Policies. Full-time Education. Curricular Activities Complement in Extra-Curricular Shift. Sports and Leisure.

\section{ACTIVIDADES CURRICULARES COMPLEMENTADAS CON UN HORARIO EXTRACLASSE EM PARANÁ: un estudio en el área de deportes y ócio}

\section{RESUMEN}

El objetivo de este estudio fue realizar un estudio sistemático de las actividades curriculares complementadas con un horario extraclasse en el area del deporte y el ocio desarrollados en las escuelas públicas de Paraná ( $\mathrm{N}=372$ ) de los diecinueve municipios caracterizados tan grande disponible en la plataforma DataEscolaBrasil (MEC), fueron analizados utilizando estadística descriptiva utilizando el programa SPSS versión 20.0. Los resultados muestran que cinco actividades complementarias del proyecto concentraron el $40,5 \%$ de las acciones en 9 areas previstas. Entre los proyectos ejecutados aproximadamente 1/3 están vinculados a area deporte y el ocio (35,4\%). En este area $64,9 \%$ de los proyectos se concentran en 5 deportes, lo que indica una tendencia a estandarizar las acciones y la prevalencia del deporte, en detrimento de otras actividades de ocio. Se concluyó que las actividades curriculares con un horario extraclasse refuerzan las acciones en apoyo de la educación general y un análisis area tiene un gran potencial en la ampliación de las oportunidades de aprendizaje para los estudiantes.

Palabras clave: Políticas Educativas. Educación Integral. Actividades Complementadas Extracurriculares. Deportes y ócio. 


\section{INTRODUÇÃO}

Nas últimas décadas, as políticas educacionais tem se ampliado gradativamente com o intuito de contribuir com a melhoria da qualidade da educação. No que se refere à educação básica as políticas educacionais tem envolvido diferentes esferas governamentais, sejam elas: federal, estadual e/ou municipal e impulsionado o desenvolvimento e criação de projetos que possuem como característica marcante a ampliação da jornada escolar para o tempo integral e a ampliação das experiências educacionais dos alunos.

Esta ampliação da jornada escolar está prevista na Lei de Diretrizes e Bases da Educação Nacional - LDBEN (BRASIL, 1996) em seu artigo 34, quando preconiza pelo gradativo aumento do tempo de permanência na escola para sete horas diárias, caracterizando-se desta forma a educação integral. Para além da ampliação da jornada escolar, conforme Krolow e Casteleins (2009, p. 3859),

A escola em tempo integral é a alternativa da aprendizagem que visa à complementação das oportunidades de aprendizagem, oferta de atividades educativas diversas, articuladas dentro do espaço escolar quanto dos demais espaços públicos.

De acordo com Gabriel e Cavalieri (2012, p. 279) a educação integral caracteriza-se como "[...] uma educação com responsabilidades ampliadas, em geral com forte atuação nas áreas da cultura, dos esportes, das artes, ultrapassando a atuação restrita à típica instrução escolar". Conforme as autoras, considerando as experiências em desenvolvimento no Brasil, é possível identificar a grosso modo, dois formatos que se caracterizam como educação integral sendo: um mais centrado na instituição escolar propriamente dita, com investimentos no interior das unidades escolares, em seus espaços e em seus profissionais e, outro, que se lança para fora da escola, buscando apoios e parcerias com agentes externos a ela.

A discussão sobre a educação integral no Brasil não é nova e sempre é remetida à possibilidade de mudança de paradigma e melhoria da qualidade da educação. De acordo com Gadotti (2009) falar em educação integral seria redundância uma vez em que não há momentos em que deixamos de nos educar. A educação se dá em tempo integral, na escola, na família, na rua, em todos os turnos, de manhã, de tarde, de noite, no cotidiano de todas as nossas experiências e vivências. Ainda segundo o autor, a concepção da educação integral que ainda se objetiva hoje enquanto política pública se ampara nas semelhanças existentes com as propostas de Anísio Teixeira para a "Escola Parque" e aos "Centros Integrados de Educação Pública", os CIEPs de Darcy Ribeiro.

Para Gadotti (2009) a concepção de educação integral é uma concepção da educação que não se confunde apenas com o horário integral, o tempo integral, ou jornada integral. A questão do tempo não seria o único fator essencial e sim a integração entre os aspectos biológico-corporais, cognitivos, afetivos e morais associados ao espaço-tempo de aprendizagem de cada indivíduo.

O autor ainda afirma que discutir os princípios de uma educação integral deve ser discutir os elementos de uma educação integrada, integradora e de tempo integral. Para 
o autor para que a educação seja integral ela deve estar integrada ao contexto social, ou seja, omnilateral e não parcial e fragmentada, bem como balizar a construção do currículo a partir da integração das diferentes possibilidades educativas. Da mesma forma, o tempo de aprender, precisa ser adequado às necessidades formativas de alunos e professores. Não se trata, portanto, de ocupar o tempo de uma jornada ampliada com atividades não escolares. Trata-se de estender, no tempo e no espaço, a sala de aula, articulando o saber científico com o saber técnico, artístico, filosófico, cultural (GADOTTI, 2009).

Ainda segundo o autor é necessário que haja uma clara distinção entre um modelo efetivamente de educação integral e iniciativas que visam simplesmente ocupar o tempo de crianças e jovens com atividades "culturais e esportivas" que pouco contribuem com o projeto educacional das escolas. E necessário a educação integral seja, portanto, vista como uma política pública.

Direcionando para a implantação da educação integral, no estado do Paraná, o Programa de Atividades Complementares Curriculares (ACCs) em contraturno escolar foi instituído na educação básica na rede estadual de ensino a partir de 2011 em caráter permanente, por meio da Resolução 1.690 de 27 de abril de 2011, da Secretaria Estadual de Educação (PARANÁ, 2011) e regulamentado pela Instrução Normativa n. 007/2012SEED/SUED (PARANÁ, 2012).

As Atividades Complementares Curriculares de Contraturno são entendidas como:

[...] atividades educativas, integradas ao Currículo Escolar, com a ampliação de tempos, espaços e oportunidades de aprendizagem que visam ampliar a formação do aluno com registro de frequência diária no livro registro de classe, inseridas no Sistema de Administração Escolar (SAE) e no Sistema Estadual de Registro Escolar (SERE) (PARANÁ, 2012).

Este Programa, que ora nos propomos a analisar pode ser classificado no segundo formato apontado por Gabriel e Cavalieri (2012), tendo em vista as características apresentadas quanto a organização das atividades, as quais "[...] podem ser desenvolvidas em outro local disponível na comunidade onde a escola está inserida, desde que não ofereça risco a integridade dos alunos" (PARANÁ, 2012). E ainda, conforme previsto no próprio objetivo do Programa de "[...] melhorar a qualidade do ensino por meio da ampliação de tempos, espaços e oportunidades educativas realizadas na escola ou no território em que está situada, em contraturno, a fim de atender às necessidades socioeducacionais dos alunos" (PARANÁ, 2012) estando de acordo com as demandas educacionais e as necessidades da comunidade.

Para Gabriel e Cavalieri (2012, p. 280) este formato de educação integral reforça "[...] os sentidos de responsabilização coletiva da sociedade pela educação das crianças e jovens", e poderíamos complementar também o fato que compreender a educação no seu sentido mais amplo, a qual não ocorre somente pela educação formal, institucionalizada, mas abrange múltiplos espaços e tempos na vida dos indivíduos, tal qual disposto no artigo primeiro da LDBEN (BRASIL, 1996) "A educação abrange os processos formativos 
que se desenvolvem na vida familiar, na convivência humana, no trabalho, nas instituições de ensino e pesquisa, nos movimentos sociais e organizações da sociedade civil e nas manifestações culturais".

O Programa está organizado em nove macrocampos que contemplam as diferentes áreas do conhecimento, sendo estes: 1) Aprofundamento da Aprendizagem, 2) Experimentação e Iniciação Científica, 3) Cultura e Arte, 4) Esporte e Lazer, 5) Tecnologias da Informação, Comunicação e Mídias, 6) Meio Ambiente, 7) Direitos Humanos, 8) Promoção de Saúde, 9) Mundo do Trabalho e Geração de Renda (PARANÁ, 2011).

Tendo como foco o macrocampo Esporte e Lazer, nos reportamos a Isayama et al (2014) quando apontam que estes aparecem relacionados inúmeras vezes no decorrer da história, e tem se fortalecido cada vez mais em diferentes cenários, dentre estes, as políticas públicas expressas em programas e projetos que possuem como finalidade ofertar diferentes práticas culturais para distintos estratos da população. Um dos fatos para isto, trata-se da representatividade das atividades físico/esportivas nos programas de lazer, o que se justifica pelo fato de que, "As atividades esportivas, na perspectiva da diversão, denominadas como recreação ou lazer, foram consideradas como estratégia importante em propostas que, por meio de vivências alegres e prazerosas, esperavam utilizar o lúdico como meio educacional" (ISAYAMA ET AL, 2014, P. 305).

Entretanto, é importante compreender que o conceito de esporte é bastante amplo e é perpassado por diferentes sentidos, ou seja: a) como um conceito teórico que busca designar uma manifestação social específica do fenômeno esporte que é duplamente ambíguo; b) como um termo técnico da política pública que recorta um tipo específico de intervenção das agências do Estado no espaço social; e, c) como uma denominação de um tipo específico de intervenção pedagógica, conotando formas particulares de intervenção no campo em que se organiza a oferta de experiências esportivas patrocinadas pelo Estado - demarcando um tipo de trabalho que se espera dos agentes executores da política pública no desenvolvimento de suas ações (GONZÁLEZ et al., 2014).

Importante compreendermos melhor a ambiguidade teórica da concepção de esporte, já que, esta é importante para a análise e entendimento das ações desenvolvidas pelo Programa ACCs em contraturno. Conforme González et al (2014, p. 36) ao utilizar o adjetivo educacional para tratar de um tipo específico de manifestação esportiva pressupõe "a existência de outras manifestações esportivas que não carregariam essa possibilidade, quando há clareza que, num sentido amplo de educação, não há prática social que não transmita sentidos e significados". Complementando, os autores se fundamentam em Bracht (2003, p. 18) quando afirma que "no sentido lato toda prática esportiva é educacional, mesmo que num sentido diverso da nossa concepção de educação".

Por outro lado, González et al (2014, p. 36) deixam claro que, não há esporte por natureza educacional num sentido restrito, uma vez que, como toda prática social, o ensino do esporte carrega a intencionalidade de seus agentes. Nesta direção, Darido (2012, p. 82) aponta que "é preciso uma intervenção pedagógica para transforma-lo [o esporte] em educativo [...]. Ou seja, estar inserido em programas de esportes, praticando esportes, não quer dizer que você está aprendendo esporte educacional". 
Nessa perspectiva, Reis et al (2015) aponta que o esporte educacional constitui empreendimento educacional específico e, como tal, diferente do esporte oferecido/tratado nas aulas de Educação Física escolar que responde, consequentemente, por um conteúdo de ensino-aprendizagem, um objeto de conhecimento que participa do processo de escolarização do qual a disciplina deve dar conta.

Conforme Manuel Sérgio (2003, p. 52) o esporte educacional possui papel importante quando se trata da renovação e transformação, já que, o mesmo "há de ser uma atividade instauradora e promotora de valores. Na prática desportiva, o Homem tem de aprender a ser mais Homem". Enquanto especificidades do esporte desenvolvido no Programa de ACCs em contraturno, compreendemos que estes princípios também devam ser respeitados, uma vez que, trata-se de uma ação vinculada ao Projeto Pedagógico das escolas que tem uma intencionalidade educacional implícita.

Diante deste entendimento, o objetivo deste estudo foi realizar um levantamento sistemático das atividades desenvolvidas pelo Programa de Atividades Complementares Curriculares de Contraturno, tendo como foco o macrocampo do esporte e lazer, nas escolas da rede pública estadual de ensino dos dezenove municípios caracterizados pelo Instituto Brasileiro de Geografia e Estatística (IBGE) como de grande porte do estado do Paraná, isto é, aqueles que possuem população igual ou superior a 100 mil habitantes. O estudo justifica-se mediante a inexistência de estudos de levantamento desta natureza de um modo geral no Estado, e mais especificamente nos municípios de abrangência da pesquisa ${ }^{4}$, o que dificulta uma compreensão mais ampla sobre sua oferta, bem como sobre questão de acompanhamento, avaliação e qualificação das ações desenvolvidas. Assim, é importante para identificar um perfil das atividades complementares mais desenvolvidas nas escolas e/ou os macrocampos mais deficitários, o que serve de parâmetro para compreender ou apontar a necessidade de investimentos na ampliação das oportunidades de aprendizagem para além daquelas relacionadas especificamente aos conteúdos da escolarização obrigatória.

\section{CAMINHOS METODOLÓGICOS PERCORRIDOS}

A presente pesquisa teve como intuito realizar um levantamento sistemático das informações acerca do desenvolvimento das políticas de educação no Paraná com vistas à inserção das atividades complementares nas escolas estaduais, por meio de uma abordagem quantitativa descritiva, recorremos a coleta e análise de dados objetivos para compreender a realidade dos municípios estudados, abrangendo de forma representativa o fenômeno em estudo e a relação entre as variáveis apresentadas.

4 Esta pesquisa configura-se como parte de uma pesquisa desenvolvida pelo Grupo de Estudos e Pesquisa em Educação Física e Esportes (GEPEFE) que possui como objetivo fazer um diagnóstico das atividades desenvolvidas pelo Programa de Atividades Complementares Curriculares de Contraturno no Paraná em municípios de grande, médio e pequeno porte I e II (IBGE, 2010). 
Como forma de coleta de dados foi utilizada a base de dados do Ministério da Educação DataEscolaBrasil ${ }^{5}$ que dispõe de informações com base no censo escolar anual. Assim, optou-se pelo levantamento de dados em municípios do estado do Paraná com população igual ou superior a 100.000 habitantes, constituindo uma amostragem total de 19 municípios ${ }^{6}$ como pode ser observado na tabela 1. A seleção das escolas fundamentou-se no atendimento aos seguintes critérios: escolas caracterizadas como públicas da rede estadual; escolas de ensino regular que atendem os níveis de educação infantil, ensino fundamental de 9 anos e ensino médio e; escolas que ofertam atividades complementares em contraturno.

Para análise estatística dos dados utilizou-se o software SPSS versão 20.0 (Statistical Package for Social Science). A normalidade dos dados foi verificada utilizando-se o teste de Kolmogorov-Smirnov, indicando o uso da estatística não-paramétrica (dados não-normais). Dessa forma, as análises foram realizadas com base na estatística descritiva como forma de compreensão do panorama de desenvolvimento das atividades complementares, adotando os modelos de análise pautados na obtenção de porcentagens, médias, frequências e cruzamento de informações. Também foram empregados os testes de correlação de Spearman e Qui-Quadrado para a verificação das diferenças observadas, adotando, portanto, o nível de significância de 0,05\%.

\section{APRESENTAÇÃO E DISCUSSÃO DOS RESULTADOS}

De acordo com a Resolução 1.690 de 27 de abril de 2011, as atividades complementares devem estar associadas ao projeto político pedagógico da escola e enquadradas em macrocampos propostos pelo documento. Importante observar que a resolução, não faz determinações sobre a necessidade e obrigatoriedade de enquadramento de projetos, seja em termos metodológicos, seja em percentuais, a qualquer um dos 9 macrocampos propostos. Compete, portanto, a escola a definição de suas iniciativas voltadas para as atividades complementares tendo como foco seu público alvo, objetivos educacionais, insumos existentes e articulação interdisciplinar com o projeto político pedagógico.

A proposição de um modelo de escola integral que adota atividades complementares como mecanismo facilitador do processo de expansão das ações educativas, é atualmente o mais presente nas políticas educacionais como mostram os estudos de Almeida da Silva e Silva (2013), Castro e Lopes (2011), Branco (2012), Felício (2011) e Cavaliere (2014). Nessa perspectiva cumpre o papel de compreender que o objetivo de uma educação integral pode ser observado pelo prisma do direito universal assegurado, proporcionando acesso a ampliação do saber constituído. A ampliação da jornada significaria, portanto, assumir via de fato que o papel social da escola se ampliou abarcando o processo educativo nas mais diversas esferas da vida social. Nesse sentido,

5 Para maiores informações: www.dataescolabrasil.inep.gov.br

6 Ressaltamos que, a capital do Estado foi excluída da pesquisa, pois conforme a caracterização do IBGE (2010) tomada como referência, municípios com mais de 1 milhão de habitantes são caracterizados como metrópole. 
Além da instrução escolar, ela estaria implicada na educação física e moral, na educação para a cidadania, na educação para a sociedade da informação e da comunicação, na difusão cultural, na socialização primária no caso das crianças pequenas e, no caso dos jovens, na formação para o trabalho. Tudo isso seria parte da justificativa para a ampliação da jornada e conformaria o que vem sendo chamado de "educação integral" (CAVALIERE, 2012, p.1207).

Enquanto política pública educacional, o modelo que associa a educação formal com projetos educativos de contraturno como forma de oferecer elementos de ampliação da jornada escolar já é uma realidade no estado do Paraná. Na tabela 1 é possível observar os municípios selecionados para este estudo, o quantitativo de escolas estaduais existentes e o quantitativo de escolas que possuem atividades do Programa ACCs em contraturno escolar.

Tabela 1 - Municípios e quantidade de escolas da pesquisa

\begin{tabular}{|c|c|c|c|c|}
\hline Municípios & $\begin{array}{l}\text { Núcleo Regional } \\
\text { de Educação }\end{array}$ & População & $\begin{array}{l}\text { Escolas } \\
\text { Estaduais }\end{array}$ & $\begin{array}{c}\text { Escolas Estaduais } \\
\text { com Atividades } \\
\text { Complementares }\end{array}$ \\
\hline Londrina & Londrina & 548.000 & 65 & 56 \\
\hline Maringá & Maringá & 397.000 & 31 & 29 \\
\hline Ponta Grossa & Ponta Grossa & 337.000 & 43 & 36 \\
\hline Cascavel & Cascavel & 312.000 & 37 & 36 \\
\hline S.J. Pinhais & NR Sul & 297.000 & 28 & 23 \\
\hline Foz do Iguaçu & Foz do Iguaçu & 263.000 & 28 & 23 \\
\hline Colombo & NR Norte & 232.000 & 22 & 13 \\
\hline Guarapuava & Guarapuava & 178.000 & 25 & 22 \\
\hline Paranaguá & Paranaguá & 150.000 & 19 & 16 \\
\hline Araucária & NR Sul & 133.000 & 16 & 9 \\
\hline Toledo & Toledo & 132.000 & 27 & 25 \\
\hline Apucarana & Apucarana & 130.000 & 16 & 15 \\
\hline Pinhais & NR Norte & 127.000 & 13 & 9 \\
\hline Campo Largo & NR Sul & 124.000 & 17 & 8 \\
\hline Arapongas & Apucarana & 115.000 & 14 & 13 \\
\hline Alm. Tamandaré & NR Norte & 112.000 & 16 & 11 \\
\hline Umuarama & Umuarama & 108.000 & 18 & 15 \\
\hline Piraquara & NR Norte & 104.000 & 10 & 2 \\
\hline Cambé & Londrina & 103.000 & 13 & 11 \\
\hline Total & & & 458 & 372 \\
\hline
\end{tabular}

Fonte: Censo IBGE (2010); DataEscolaBrasil (2016). 
Observa-se que o quantitativo de escolas estaduais que desenvolvem atividades complementares nos municípios pesquisados é da ordem de $81,44 \%$, o que infere que a aplicabilidade dessas ações pode ser considerada como em processo de consolidação, uma vez que, a resolução estadual que instituiu as atividades complementares classifica-as como de caráter permanente e/ou periódico ${ }^{7}$ e com vistas à implementação progressiva do ensino em tempo integral. Importante destacar que, os dados referentes a classificação das atividades não encontram-se disponíveis na plataforma, o que gera uma lacuna com relação ao caráter das atividades desenvolvidas nos municípios pesquisados. O quantitativo de escolas que aderiram ao Programa de ACCs apresenta-se como aspecto positivo, uma vez que, "Percebe-se uma tendência de enriquecimento da educação formal, dando a escola maior flexibilidade em sua organização e em seu horizonte formativo" (CARNEIRO, 2015, p. 411).

A legitimação de alguns conteúdos a serem propostos como atividade complementar está relacionada ao modelo de gestão adotado pela escola e a forma como a comunidade escolar observa e se apropria da expansão das possibilidades de ações pedagógicas. Nesse sentido a educação integral surgiria como resposta às reivindicações das classes populares, com a implantação de projetos de escolas de tempo integral, cuja motivação seria a tentativa de amenizar os problemas sociais, além dos muros escolares, ainda que estes problemas não tenham "natureza propriamente pedagógica" (PARO, 1988).

Observa-se que a oferta de determinados conteúdos, especialmente a partir dos macrocampos propostos pela Instrução Normativa 07/2012 (PARANÁ, 2012), tende a posicionar tal política educacional como uma ferramenta de formação humana complementar que objetiva, dentre outros fatores, a melhoria dos índices educacionais propostos por mecanismos de avaliação sistemáticos externos, a partir da prerrogativa da "qualidade na educação". De acordo com Bendrath (2008) os padrões educacionais tendem, no contexto mundial, a serem colocados como fator comparativo uma vez que a formação do capital humano é vital para o início do desenvolvimento local e, consequentemente, para uma abertura maior da economia. Nesse sentido, reforçar uma formação direcionada ao interesse estatal a partir de conteúdos articuladores, possibilita assegurar que o capital humano de amanhã se adapte as exigências e demandas interpostas por agências transnacionais, posicionando a educação como commodity.

Nesse contexto, políticas compensatórias são desenvolvidas a partir de lacunas identificadas pela ausência de ações que resultem em eficiência e efetividade social em políticas públicas ${ }^{8}$. Ações voltadas para as atividades curriculares complementares indicam um fator compensatório ao direcionar macrocampos de ação paralelos ao currículo

7 De acordo com a referida Resolução, as atividades classificadas como de caráter permanente, caracterizam-se por ser ofertadas em, no mínimo, 16h/a semanais, distribuídas nos 5 dias letivos, para um mesmo grupo de alunos, de mesma série/ano. Já as atividades de caráter periódico soa ofertadas com, no mínimo, 4 h/a semanais para grupos de alunos de mesma série/ano ou séries/anos diferentes (PARANÁ, 2011).

8 O conceito de eficiência, eficácia e efetividade social, são fatores fundamentais no processo de avaliação em políticas públicas e análises a partir de tais pressupostos podem nortear a correção e possibilitar a melhoria de sistemas públicos. Para mais informações ver Belloni, Magalhães e Sousa (2007) 
formal. Tais ações teriam por objetivo assegurar uma formação emancipatória ou garantir o simples cumprimento de metas? Para Chirinéa e Brandão (2015) é a partir da década de 1990 com a reforma do Estado que a concepção de qualidade de ensino passou a ser significativamente pautada pelas notas e pelos resultados obtidos por meio das avaliações externas. Ainda segundo os autores a busca da qualidade na educação não é referência para a consolidação do direito do cidadão em exercer sua participação política e social. A busca da qualidade está muito mais ligada ao desenvolvimento econômico do país, bem como sua inserção no grupo dos países desenvolvidos. Ampliar as possibilidades educativas, e legitimar determinados conteúdos em específico justificam-se na medida em que o Estado atrela-os ao preceito da melhoria da qualidade da educação. A qualidade, portanto, emergeria da necessidade de se prepararem os indivíduos para processos mentais cada vez mais requintados e abstratos (CHIRINÉA, BRANDÃO, 2015)

\begin{abstract}
A qualidade, nesse sentido, não é uma qualidade que emerge do núcleo formador da escola e dos sistemas de ensino como direito do cidadão, mas uma qualidade concebida por agências multilaterais, com o propósito de diminuir a taxa de pobreza dos países em desenvolvimento e de adequar a educação a uma reestruturação produtiva. (CHIRINÉA, BRANDÃO, 2015, p.465)
\end{abstract}

Ao observamos as ações práticas desenvolvidas nas escolas, pudemos constatar que há variações pontuais nas ações desenvolvidas, o que indica uma flexibilidade de uma política compensatória pontual que se adapta as necessidades emergentes de cada unidade escolar, porém, balizadas por eixos norteadores bem definidos pelo Estado.

A diversidade de oferta de projetos em contraturno indicam caminhos distintos entre as opções de oferta de projetos nas escolas pesquisadas. As atividades cujas características vão desde complementos à aprendizagem curricular, até esportes e formação para o mercado de trabalho, apontam para reflexões sobre as possíveis relações intrínsecas existentes (ou não) entre os diferentes processos educativos que passam a vigorar no ambiente escolar a partir de uma educação integral tal qual o proposto. O foco, portanto, deveria estar concentrado no processo de melhoria da qualidade da educação.

Os projetos elaborados e desenvolvidos no Brasil evidenciam a necessidade de atrelar a expansão do tempo de permanência do educando na escola à melhoria da qualidade do ensino oferecido, quando explicitam o compromisso de criar oportunidades reais para que os educandos possam se desenvolver em sua plenitude (FELÍClO, 2011, p.165).

Nessa perspectiva os dados levantados apresentaram indicativos de maior concentração de projetos em determinados macrocampos em contraposição a ausência de projetos em outros, indicando haver um consenso de aplicabilidade nas áreas de Esporte e Lazer e Aprofundamento da Aprendizagem, como pode ser observado tabela 2. 
Tabela 2 - Principais Atividades Complementares desenvolvidas.

\begin{tabular}{|c|c|c|}
\hline Atividade & FA & FR \\
\hline Línguas Estrangeiras & 261 & 18,4 \\
\hline Futsal & 138 & 9,8 \\
\hline Voleibol & 69 & 4,9 \\
\hline Leitura de Produção de texto & 53 & 3,7 \\
\hline Atletismo e múltiplas vivências esportivas & 50 & 3,5 \\
\hline Economia solidária e criativa & 45 & 3,2 \\
\hline Danças & 41 & 2,9 \\
\hline Tênis de mesa & 36 & 2,5 \\
\hline Orientação de estudos e leitura & 35 & 2,5 \\
\hline Atletismo & 32 & 2,3 \\
\hline Xadrez & 32 & 2,3 \\
\hline Conservação de solo e composteira & 31 & 2,2 \\
\hline Teatro & 31 & 2,2 \\
\hline Outra categoria de acompanhamento pedagógico & 26 & 1,8 \\
\hline Matemática & 25 & 1,8 \\
\hline Basquete & 24 & 1,7 \\
\hline Outra categoria de esporte e lazer & 24 & 1,7 \\
\hline Handebol & 23 & 1,6 \\
\hline Letramento e alfabetização & 23 & 1,6 \\
\hline Outra categoria de artes, cultura e educação patrimonial & 22 & 1,6 \\
\hline Rádio escolar & 20 & 1,4 \\
\hline Canto coral & 19 & 1,3 \\
\hline Música & 18 & 1,3 \\
\hline Percussão & 18 & 1,3 \\
\hline Jornal escolar & 17 & 1,2 \\
\hline Iniciação científica & 16 & 1,1 \\
\hline
\end{tabular}

Fonte: pesquisa autores, 2016.

Conforme pode ser observado na tabela 2, as principais atividades complementares desenvolvidas nas escolas atingem o percentual de 79,8\%, distribuídas em 26 diferentes projetos. Importante ressaltar que, dentre estes projetos 10 estão vinculados ao macrocampo Esporte e Lazer, como pode ser verificado nos projetos destacados na tabela 2. As demais atividades desenvolvidas 20,2\% apresentam um percentual relativo menor que $1 \%$, e estão distribuídas nos 9 macrocampos possíveis, perfazendo um total de 57 diferentes projetos de atividades complementares. 
È possível ainda observar na tabela 2 que, as 5 atividades complementares mais desenvolvidas nas escolas estaduais dos municípios (línguas estrangeiras, futsal, voleibol, leitura e produção de texto, e, atletismo e múltiplas vivências esportivas) correspondem a $40,5 \%$ de todas as atividades. Estas atividades identificadas como as mais evidentes estão enquadradas em dois macrocampos, sendo que, 22,3\% estão no macrocampo Aprofundamento da aprendizagem e 18,2\% no macrocampo Esporte e Lazer.

Estes dados possuem semelhanças com a pesquisa realizada em $2008^{9}$ em todo o território nacional, onde constatou-se que as atividades mais desenvolvidas nas experiências de jornada escolar ampliada eram referentes as áreas de Esportes (65\%) e Aulas de reforço $(61,7 \%)$. Entretanto, a atividade que atualmente identificamos como a que abrange o maior número de projetos nas escolas estaduais paranaenses, línguas estrangeiras (18,5\%) na pesquisa acima citada aparecia na décima terceira posição com 17,8\% (CARNEIRO, 2015, p. 414).

Os dados levantados suscitam alguns pontos para reflexão, tais como: quais seriam os fatores que potencializam que apenas 5 projetos de atividades complementares concentrem 40,5\% de todas as ações? Que fatores contribuem para que, os macrocampos com maior concentração de atividades estejam relacionados com as atividades que são desenvolvidas no turno obrigatório da educação formal? O Programa está atingindo seu objetivo de oportunizar amplas e diversificadas formas de aprendizagem considerando esta concentração de atividades? Quais os fatores que contribuem para que, no macrocampo do Esporte e Lazer, modalidades entendidas como tradicionais da área (futsal, voleibol, atletismo) se sobressaem perante as inúmeras possibilidades que poderiam ser exploradas, no sentido de ampliação das vivências oportunizadas pelo macrocampo?

Tais indagações forçosamente levam a tentativa de compreensão do papel do Programa e, mais especificamente, do papel do esporte e lazer dentro da escola e sua representatividade no universo amplo das atividades complementares. A estratificação dos dados por projetos e suas respectivas cidades trouxe à tona a maior dimensão global do macrocampo do Esporte e Lazer em relação aos demais como pode ser visto na tabela 3.

9 Pesquisa "Educação Integral/Educação Integrada e(m) tempo integral: concepções e práticas na educação brasileira", realizada em parceria pelas universidades: UFPR, UnB, UNIRIO, UFRJ, UERJ, UFMG. 
Tabela 3 - Comparação do macrocampo Esporte e Lazer

\begin{tabular}{|c|c|c|c|c|c|c|}
\hline \multirow[t]{3}{*}{ Município } & \multicolumn{4}{|c|}{$\begin{array}{c}\text { Existência de projetos } \\
\text { na área de Esporte e Lazer* }\end{array}$} & \multirow{2}{*}{\multicolumn{2}{|c|}{$\begin{array}{l}\text { Total de Projetos } \\
\text { existentes }\end{array}$}} \\
\hline & \multicolumn{2}{|c|}{ Esporte e Lazer } & \multicolumn{2}{|c|}{ Outra Área } & & \\
\hline & FA & FR & FA & FR & FA & FR \\
\hline Londrina & 65 & $31,4 \%$ & 142 & $68,6 \%$ & 207 & $100 \%$ \\
\hline Maringá & 50 & $42,7 \%$ & 67 & $57,3 \%$ & 117 & $100 \%$ \\
\hline Ponta Grossa & 54 & $37,8 \%$ & 89 & $62,2 \%$ & 143 & $100 \%$ \\
\hline Cascavel & 49 & $32,2 \%$ & 103 & $67,8 \%$ & 152 & $100 \%$ \\
\hline São José dos Pinhais & 23 & $36,5 \%$ & 40 & $63,5 \%$ & 63 & $100 \%$ \\
\hline Foz do Iguaçu & 37 & $38,1 \%$ & 60 & $61,9 \%$ & 97 & $100 \%$ \\
\hline Colombo & 12 & $50,0 \%$ & 12 & $50,0 \%$ & 24 & $100 \%$ \\
\hline Guarapuava & 29 & $30,9 \%$ & 65 & $69,1 \%$ & 94 & $100 \%$ \\
\hline Paranaguá & 15 & $21,1 \%$ & 56 & $78,9 \%$ & 71 & $100 \%$ \\
\hline Araucária & 2 & $14,3 \%$ & 12 & $85,7 \%$ & 14 & $100 \%$ \\
\hline Toledo & 34 & $30,9 \%$ & 76 & $69,1 \%$ & 110 & $100 \%$ \\
\hline Apucarana & 30 & $42,3 \%$ & 41 & $57,7 \%$ & 71 & $100 \%$ \\
\hline Pinhais & 12 & $38,7 \%$ & 19 & $61,3 \%$ & 31 & $100 \%$ \\
\hline Campo Largo & 14 & $51,9 \%$ & 13 & $48,1 \%$ & 27 & $100 \%$ \\
\hline Arapongas & 25 & $43,9 \%$ & 32 & $56,1 \%$ & 57 & $100 \%$ \\
\hline Almirante Tamandaré & 13 & $32,5 \%$ & 27 & $67,5 \%$ & 40 & $100 \%$ \\
\hline Umuarama & 20 & $37,0 \%$ & 34 & $63,0 \%$ & 54 & $100 \%$ \\
\hline Piraquara & 5 & $71,4 \%$ & 2 & $28,6 \%$ & 7 & $100 \%$ \\
\hline Cambé & 12 & $33,3 \%$ & 24 & $66,7 \%$ & 36 & $100 \%$ \\
\hline Total & 501 & $35,4 \%$ & 914 & $64,6 \%$ & 1415 & $100 \%$ \\
\hline
\end{tabular}

*Qui-quadrado: 29,514 ( $p=0,042)$

Fonte: pesquisa autores, 2016

O levantamento geral indica que da ordem de 1/3 dos projetos executados dentro das atividades complementares nas escolas são de origem do macrocampo Esporte e Lazer, no entanto, uma análise mais precisa não indica padronização dessa divisão uma vez que a diferença estatística existente entre os municípios foi considerada significativa $(p=0,042)$.

A importância do esporte como mecanismo educativo que pode, dentre outros fatores, atuar na socialização, no desenvolvimento de habilidades e competências, bem como promover a saúde, pode ser interpretada como elemento facilitador durante o processo de tomada de decisão para a implantação dos projetos nas escolas. Por meio de ações desta natureza, é possível criar situações capazes de, para além de conscientizar o 
aluno sobre a importância de frequentar as aulas, suas experiências no contraturno, possibilitam a descoberta de que ele "[...] poderá ter uma vida mais saudável interagindo com outros alunos, somando valores, aumentando seu rendimento físico, intelectual e social, despertando a vontade de estar envolvido ativamente na prática educativa" (KROLOW; CASTELLEINS, 2009. p.3).

Do ponto de vista da gestão dos projetos, estes aspectos podem influenciar positivamente o potencial de gerar matrículas nas atividades complementares nas escolas, bem como de ampliar o número de projetos e qualificar cada vez mais as ações desenvolvidas, seja em termos de ações desenvolvidas, seja na busca pela ampliação de recursos, melhorias de estruturas, e qualificação dos profissionais envolvidos.

Com relação ao número de matriculas, os dados levantados indicam que, o macrocampo Esporte e Lazer concentra aproximadamente 35,4\% dos projetos executados e possui um total de matrículas que atinge $32,21 \%$.

Tabela 4 - Média de matrícula nos projetos

\begin{tabular}{cccccccc}
\hline \multicolumn{3}{c}{ Área de Esporte e Lazer } & \multicolumn{5}{c}{ Demais Áreas } \\
\hline $\begin{array}{l}\text { Total de } \\
\text { Projetos }\end{array}$ & $\begin{array}{c}\text { Total } \\
\text { Matrículas }\end{array}$ & $\begin{array}{c}\text { Média de } \\
\text { alunos }\end{array}$ & \pm & $\begin{array}{c}\text { Total de } \\
\text { Projetos }\end{array}$ & $\begin{array}{c}\text { Total } \\
\text { Matrículas }\end{array}$ & $\begin{array}{c}\text { Média } \\
\text { de alunos }\end{array}$ & \pm \\
\hline 501 & 19.597 & 39,12 & 25,0 & 914 & 41.242 & 45,12 & 29,3 \\
\hline $32,21 \%$ & do total de matrículas & & & $67,79 \%$ & do total de matrículas \\
\hline
\end{tabular}

Fonte: pesquisa autores, 2016.

Dos 60.839 alunos matriculados em atividades complementares nas escolas estaduais do Paraná pertencentes aos municípios pesquisados nesse estudo, 19.597 alunos estão vinculados a atividades de Esporte e Lazer, indicando que 1/3 das atividades desenvolvidas estão direcionadas a esse macrocampo.

O macrocampo Esporte e Lazer, a partir dos dados observados, segue uma tendência de similitude de ações, uma vez que $64,9 \%$ dos projetos estão concentrados em apenas 5 tipos de modalidades como pode ser observado na tabela 5.

Quando observadas as disposições de frequência de implantação de projetos por município é possível notar que a similitude em relação às iniciativas tende a se manter não havendo distorções em relação as opções existentes nas possíveis atividades a serem desenvolvidas no referido macrocampo. No entanto, foi possível observar uma correlação positiva ( $r=0,97$ em $p=0,0001$ ) entre quantidade de projetos (modalidade) e matrícula (taxa).

Ao observar a disposição dos projetos do macrocampo Esporte e Lazer nos municípios do estudo, constata-se que a taxa média de matrícula em 16 municípios é superior a 30 alunos por projeto, sendo que dessas, em 8 municípios o número é superior a 40 alunos (Tabela 6), ou seja, superior à media encontrada no conjunto de todas as cidades analisadas. 
Tabela 5 - Cinco maiores frequências de projetos no macrocampo Esporte e Lazer

\begin{tabular}{lcccc}
\hline \multirow{2}{*}{ Projetos } & \multicolumn{2}{c}{ Quantidade Projetos } & \multicolumn{2}{c}{ Matrículas } \\
\cline { 2 - 5 } & FA & FR \% & Matrículas & Média Matrícula \\
\hline Futsal & 138 & 27,5 & 4.628 & 33,5 \\
Voleibol & 69 & 13,8 & 2.470 & 35,7 \\
Atletismo e múltiplas vivências & 50 & 10,0 & 2.846 & 56,9 \\
esportivas & 36 & 7,2 & 1.570 & 43,6 \\
Tênis de Mesa & 32 & 6,4 & 1.433 & 44,7 \\
Atletismo & 176 & 35,1 & 6.650 & 37,7 \\
Demais projetos & 501 & 100,0 & 19.597 & 39,1 \\
\hline Total & & & \\
\hline R=0,97 $(p=0,001)$ & &
\end{tabular}

Fonte: pesquisa autores, 2016.

Tabela 6 - Quantidade de projetos e matrículas do macrocampo Esporte e Lazer

\begin{tabular}{lccc}
\hline \multirow{2}{*}{ Municípios } & \multicolumn{3}{c}{ Macrocampo Esporte e Lazer } \\
\cline { 2 - 4 } & Total Projetos & Total Matrículas & Média Matrículas \\
\hline Londrina & 65 & 2.276 & 35,0 \\
Maringá & 50 & 1.680 & 33,6 \\
Ponta Grossa & 54 & 2.295 & 42,5 \\
Cascavel & 49 & 2.207 & 45,0 \\
São J. Pinhais & 23 & 1.080 & 47,3 \\
Foz do Iguaçu & 37 & 1.545 & 41,7 \\
Colombo & 12 & 371 & 30,9 \\
Guarapuava & 29 & 1.247 & 43,0 \\
Paranaguá & 15 & 497 & 33,1 \\
Araucária & 2 & 30 & 15,0 \\
Toledo & 34 & 1.230 & 36,1 \\
Apucarana & 30 & 1.313 & 43,7 \\
Pinhais & 12 & 566 & 47,1 \\
Campo Largo & 14 & 335 & 23,9 \\
Arapongas & 25 & 800 & 32,0 \\
Alm. Tamandaré & 13 & 803 & 61,7 \\
Umuarama & 20 & 770 & 38,5 \\
Piraquara & 5 & 130 & 26,0 \\
Cambé & 12 & 414 & 34,5 \\
\hline Total & 501 & 19.597 & 39,1 \\
\hline Fonte: & & &
\end{tabular}

Fonte: pesquisa autores, 2016 
Analisando os dados por município (tabela 7), observa-se que o destaque no macrocampo Esporte e Lazer fica por conta de 5 modalidades específicas de esporte que figuram como as de maior frequência de implantação nos 19 municípios: Futsal figura como maior frequência em 11 municípios totalizando 140 projetos; Atletismo em 4 municípios totalizando 29 projetos; Voleibol em 2 municípios totalizando 10 projetos, e; Tênis de Mesa e Futebol em um municípios cada, totalizando 3 e 1 projetos respectivamente.

A prevalência do esporte em um macrocampo ao qual também faz parte o lazer é inegável e absoluto, relegando um papel de coadjuvante para projetos cujas características desempenhem valores e diretrizes associadas ao campo do lazer como prática possível na escola pública. Conforme Castellani Filho (2013, p. 13) “O esporte e o lazer constituem-se em conceitos distintos, nos quais o último não pode ser reduzido às fronteiras do primeiro". O autor relata que esta relação entre esporte e lazer, no que tange a manifestação do esporte de participação, há a necessidade de incorporar uma política específica, ou seja, agregar uma política de lazer que não desenvolva apenas os interesses físico-esportivos, mas que contemplem uma série de interesses presentes em nosso quadro cultural.

Para que o lazer não exerça somente o papel de coadjuvante no Programa, recorremos a Marcellino (2003) quando aponta a importância de uma "educação para o lazer" que contribua para a demonstração da importância do lazer, como forma de expressão humana, na nossa sociedade, para a formação não só de praticantes, mas também de espectadores ativos, críticos e criativos e para a incorporação no processo educacional do elemento lúdico da cultura, enquanto estratégia de ensino.

As maiores frequências de implantação de projetos de Esporte e Lazer (Tabela 7) seguem a tendência de padronização de modalidades já consagradas na Educação Física escolar e presentes nos conteúdos programáticos dos PCNs da área. Este dado deve ser ressaltado quando nos reportamos aos objetivos do Programa ACCs de ampliar as oportunidades educativas dos alunos, uma vez que, as características incorporadas pelo Programa podem estar deixando lacunas no que se refere ao alcance deste objetivo. Entretanto, esta escolha pode estar relacionada, entre outros fatores, a capacitação dos professores para desenvolver atividades diferenciadas, a estrutura disponível na escola - ou fora dela, no caso de parcerias - e os custos de financiamento do Programa.

Objetivando compreender as ACCs como ferramenta inicial para a transformação da educação pública paranaense como de tempo integral, o leque de variedade de ações deve proporcionar aos alunos uma formação educacional sólida. Segundo Gadotti (2009) a escola de tempo integral deve proporcionar estudos complementares e atividades de esporte, cultura, lazer, estudos sociais, línguas estrangeiras, cuidados de saúde, música, teatro, cultivo da terra, canto, ecologia, artesanato, corte e costura, informática, artes plásticas, potencializando o desenvolvimento da dimensão cognitiva e ao mesmo tempo afetiva e relacional dos alunos, entre outras. Não se trata apenas de estar na escola em horário integral, mas de ter a possibilidade de desenvolver todas as potencialidades humanas, que envolvem o corpo, a mente, a sociabilidade, a arte, a cultura, a dança, a música, o esporte, o lazer. 
Tabela 7 - Projetos com maior frequência no macrocampo de Esporte e Lazer por município

\begin{tabular}{lcccc}
\hline \multirow{2}{*}{ Município } & $\begin{array}{c}\text { Total de } \\
\text { Projetos em } \\
\text { todas áreas }\end{array}$ & Principais Projetos na área de Esporte e Lazer & FA & FR \% (cidade) \\
\cline { 3 - 5 } Londrina & 207 & Futsal & 45 & 21,7 \\
Maringá & 117 & Futsal & 14 & 12,0 \\
Ponta Grossa & 143 & Futsal & 16 & 11,2 \\
Cascavel & 152 & Futsal & 17 & 11,2 \\
São J. Pinhais & 63 & Atletismo & 5 & 7,9 \\
Foz do lguaçu & 97 & Atletismo & 10 & 10,3 \\
Colombo & 24 & Futsal & 4 & 16,7 \\
Guarapuava & 94 & Atletismo & 11 & 11,7 \\
Paranaguá & 71 & Tênis de Mesa & 3 & 4,2 \\
Araucária & 14 & Futebol & 1 & 7,1 \\
Toledo & 110 & Futsal & 12 & 10,9 \\
Apucarana & 71 & Futsal & 11 & 15,5 \\
Pinhais & 31 & Futsal & 3 & 9,7 \\
Campo Largo & 27 & Futsal & 6 & 22,2 \\
Arapongas & 57 & Voleibol & 6 & 10,5 \\
Alm. Tamandaré & 40 & Atletismo & 3 & 7,5 \\
Umuarama & 54 & Futsal & 8 & 14,8 \\
Piraquara & 76 & Futsal & 2 & 28,6 \\
Cambé & Voleibol & 4 & 11,1 \\
\hline Fonte: & & & &
\end{tabular}

Fonte: pesquisa autores, 2016.

Compreendendo estas especificidades, a busca pela qualificação das ações deve ser constante e estar orientada por princípios coletivos. Sobre esta questão, Costa, Armbrust, Teramoto (2014) quando escrevem sobre a qualificação da Educação Física Curricular e a necessidade de reflexão e sistematização da prática pedagógica nas escolas, apontam que ao trabalhar o esporte é necessário contemplar a dimensão do direito a aprender e favorecer o desenvolvimento de uma postura ativa dos alunos frente à aprendizagem, pautando-se nos seguintes princípios: inclusão de todos, construção coletiva, respeito a diversidade, educação integral, autonomia, ensinar como direito de todos e, ensinar bem para todos. Embora estes princípios foram pensados a partir das práticas da Educação Física curricular, acreditamos que os mesmos devem ser atendidos considerando as especificidades do Programa ACCs em contraturno, devido a necessidade de articulação com o projeto político pedagógico das escolas e aos próprios objetivos do Programa. 
Uma observação que deve ser feita é o intuito não diretivo das ACCs enquanto política compensatória de minimizar as diferenças existentes entre os sistemas público e privado de educação, onde a oferta de atividades extracurriculares em contraturno potencializaria o processo de aprendizagem dos alunos.

As propostas atuais de tempo integral estão muito mais preocupadas em estender o direito de passar "mais tempo na escola" às camadas mais pobres da população. A escola privada das classes médias e ricas já é de tempo integral. Pode-se dizer que o aluno da escola privada dispõe de tempo integral dedicado a sua educação. Geralmente ele dispõe de um "contraturno", com aulas complementares de esporte, lazer, reforço em línguas estrangeiras, balé, judô etc. (GADOTTI, 2009, p.32)

O desenvolvimento de projetos sem a devida articulação com os projetos políticos pedagógicos da escola, e sem uma propositura real associada a uma formação emancipatória poderá comprometer os objetivos em si da política, uma vez que apenas a ampliação da jornada com atividades complementares para equiparação ao sistema particular de ensino poderia não resultar na melhoria da qualidade da educação, uma vez outros fatores como formação docente, proposta pedagógica, espaço físico, insumos materiais, relação aluno/ professor não são ponderados na equação. O fator tempo, seria, portanto, apenas uma variável dentre muitas outras ao qual o Estado necessita equalizar.

\section{CONSIDERAÇÕES FINAIS}

A pesquisa possibilitou a compreensão estrutural da divisão das atividades complementares a partir dos macrocampos propostos pela Resolução 1.690/2011 nos municípios do estado do Paraná com população superior a 100.000 habitantes. Os resultados evidenciaram que cinco projetos de atividades complementares se sobressaem nas escolas pesquisadas, abrangendo 40,5\% e estão concentradas em dois macrocampos. Estes resultados apontam para algumas reflexões que vão de encontro com os objetivos do Programa, uma vez que, ao concentrar as atividades em macrocampos específicos atende parcialmente a necessidade de ampliação das oportunidades de aprendizagem, ou mesmo restringe a campos específicos do conhecimento identificados como necessidades e que não são atendidos plenamente pela educação formal, como por exemplo, os projetos na área de línguas estrangeiras e/ou leitura e produção de texto.

Considerando especificamente o macrocampo Esporte e Lazer, o destaque para os projetos na área do esporte pode estar relacionado com questões referentes a infraestrutura; formação dos profissionais que desenvolvem estas atividades e a visibilidade da escola por meio destes projetos, haja vista que, muitos estão voltados ao treinamento de modalidades para competições esportivas escolares, como fora constatado por Luguetti; Bastos: Bohme (2011) em estudo realizado no município de Santos-SP, onde as atividades em contraturno escolar são denominadas "práticas esportivas escolares" ou mesmo "turmas de treinamento esportivo" e os profissionais que desenvolvem são chamados de professores/treinadores. 
Nesse mesmo sentido, os dados apresentados nas tabelas 5, 6 e 7 nos fazem refletir se a proposta do Programa ACCs torna-se diferenciadas em sua essência e objetivos-fim, isto é, se configuram-se como uma ampliação das oportunidades de aprendizagem como preconizam os objetivos do Programa ou, tornam-se uma extensão não-obrigatória das aulas curriculares do componente Educação Física que aborda os mesmos conteúdos das aulas.

Por outro lado, os resultados desta pesquisa também apontam para a importância das atividades no macrocampo Esporte e Lazer, quando considerado o número de projetos, o quantitativo de modalidade e o número de matrículas. Desta forma, compreendemos que as atividades complementares curriculares em contraturno reforçam ações em prol da educação integral, e que a livre possibilidade de direcionamento dos projetos pelos 9 macrocampos favorecem iniciativas esportivas pelo seu dinamismo e maior proximidade com os interesses dos alunos, já que, a adesão aos projetos não é tratado como obrigatoriedade e sim, uma participação voluntária que parte do interesse dos alunos.

Neste sentido, a educação em tempo integral como política em construção assume, nas experiências em curso, diferentes perspectivas teóricas e configurações concretas. Como pode ser verificado, tanto nos dados levantados quanto em outras experiências publicadas, de modo geral, a educação em tempo integral tem sido pensada sob os aspectos da ampliação das oportunidades educativas e formação integral dos sujeitos, da proteção e garantia dos direitos básicos às crianças e aos adolescentes, para os quais, em muitos casos a escola se configura como ambiente central de acesso à cultura, à alimentação, à assistência e à proteção.

Portanto, a educação em tempo integral é vista como um processo em construção no país, e as experiências em andamento, na mesma medida em que buscam a ampliação qualitativa e do tempo escolar, enfrentam dificuldades inerentes à formação profissional e a própria estrutura física e pedagógica instituída na escola. Fato este, que pode estar direcionando a concentração da oferta de atividades complementares em determinados macrocampos.

Como limitações do estudo, apontamos a impossibilidade de conhecer os critérios de implantação e escolha das atividades desenvolvidas, de avaliar a forma como efetivamente acontecem os Projetos dentro do Programa analisado, qual a situação real no que se refere a frequência de participação dos alunos matriculados, bem como a forma como são desenvolvidos os projetos, em termos de objetivos, planejamento e estratégias para a realização das atividades. Apesar das limitações sugeridas, o estudo traz um incentivo à necessidade de se aprofundar as pesquisas relativas a esta temática com vistas a contribuir com a melhoria da qualidade da educação tendo como uma das estratégias a efetiva implantação e ampliação da educação em tempo integral.

\section{REFERÊNCIAS}

ALMEIDA DA SILVA, Jamerson Antonio de; SILVA, Katharine Ninive Pinto. A hegemonia às avessas no Programa Mais Educação. Revista Brasileira de Estudos Pedagógicos. Brasília, v. 94, n. 238, set/dez 2013, p. 701-720 
julho/2017

BELLONI, Isaura; MAGALHÃES, Heitor de; SOUSA, Luzia Costa de. Metodologia de Avaliação em Políticas Públicas. 4ed. São Paulo, Cortez. 2007

BENDRATH, Eduard Angelo. A educação como commodity: a política de organismos internacionais. Colloquium Humanarum, Presidente Prudente, v. 5, n. 1, p. 47-58, jun. 2008

BRACHT, Valter. Sociologia Crítica do Esporte: uma introdução. ljuí: Ed. Unijuí, 2003.

BRANCO, Verônica. Desafios para a implantação da Educação Integral: análise das experiências desenvolvidas na região sul do Brasil. Educar em Revista. Curitiba. N.45, jul/set. 2012, p.111-123

BRASIL. Lei 9.394, de 20 de dezembro de 1996: Lei de Diretrizes e Bases da Educação Nacional. Senado Federal. Secretaria Especial de Editoração e Publicações. Subsecretaria de Edições Técnicas. Brasília. 1996.

CARNEIRO, Moaci Alves. LDB fácil: leitura crítico-compreensiva artigo a artigo. 23. ed. Petrópolis, RJ: Vozes, 2015.

CASTELLANI FILHO, L. Educação física, esporte e lazer: reflexões nada aleatórias. Campinas, SP: Autores Associados, 2013.

CASTRO, Adriana de; LOPES, Roseli Esquerdo. A escola de tempo integral: desafios e possibilidades. Ensaio: aval. pol. públ. Educ. Rio de Janeiro. V.19, N.71. abr/jun 2011, p. 259-282

CAVALIERE, Ana Maria. Escola pública de tempo integral no Brasil: filantropia ou política de estado? Educação \& Sociedade. Campinas, V.35, N.129, out-dez 2014, p.1205-1222.

CHIRINÉA, Andrea Melanda; BRANDÃO, Carlos da Fonseca. O IDEB como política de regulação do Estado e legitimação da qualidade: em busca de significados. Ensaio: aval. pol. públ. Educ., Rio de Janeiro, v. 23, n. 87, p. 461-484, abr./jun. 2015

COSTA, Caio Martins; ARMBRUST, Igor; TERAMOTO, Willian Oliveira. Qualificação da Educação Física Curricular: Reflexão e sistematização da prática pedagógica nas escolas. São Paulo: Instituto Esporte Educação, 2014.

DARIDO, S. C. Esporte e educação: uma relação imprescindível. In: GOELLNER, S. V.; SOARES, L. S.; CARVALHO, M. A. A. de. (org.) Programa Segundo Tempo: memória, experiências, avaliação e perspectivas no encontro das equipes colaboradoras. Maringá: Eduem, 2012, p. 81-106.

FELÍCIO, Helena Maria dos Santos. A instituição formal e a não-formal na construção do currículo de uma escola de tempo integral. Educação em Revista. Belo Horizonte. V.27, N.3, dez.2011, p.163-182

GABRIEL, Carmen Teresa; CAVALIERI, Ana Maria. Educação Integral e currículo integrado: quando dois conceitos se articulam em um programa. In: MOLL, Jaqueline et al. Caminhos da Educação Integral no Brasil: direito a outros tempos e espaços educativos. Porto Alegre: Penso, 2012.

GADOTTI, Moacir. Educação Integral no Brasil: inovações em processo. São Paulo. Editora Paulo Freire, 2009

GONZÁLEZ, Fernando Jaime et al. Nas pegadas do esporte educacional. In: MARINHO, Alcyane; NASCIMENTO, Juarez Vieira; OLIVEIRA, Amauri Bassoli de (orgs.). Legados do Esporte Brasileiro. Florianópolis: Ed. da UDESC, 2014. p. 35-43. 
IBGE. Instituto Brasileiro de Geografia e Estatística. Pesquisa Nacional por Amostra de Domicílios. Síntese dos Indicadores de 2009. Rio de Janeiro: IBGE, 2010.

KROLOW, Aderlei Correa Milech; CASTELEINS, Vera Lucia. Contra turno: Um espaço de desafio para a educação do futuro. In: IX Congresso Nacional de Educação. Anais..., Curitiba, 2009.

LUGUETTI, Carla Nascimento; BASTOS, Flávia da Cunha; BÖHME, Maria Tereza Silveira. Gestão de práticas esportivas escolares no ensino fundamental no município de Santos.

Revista Brasileira de Educação Física e Esporte, São Paulo, v.25, n.2, p.237-49, abr./ jun. 2011.

MARCELLINO, Nelson Carvalho. Lazer e educação. 10. ed. Campinas: Papirus, 2003.

MOLL, Jaqueline et al. Caminhos da Educação Integral no Brasil: direito a outros tempos e espaços educativos. Porto Alegre: Penso, 2012.

PARANÁ. Secretaria do Estado da Educação. Superintendência da Educação. Instrução

$\mathbf{n}^{\circ}$ 007/2012-SEED/SUED. Dispõe sobre o Programa de Atividades Complementares Curriculares em contraturno, nas instituições de ensino da Rede Estadual. Paraná, 2012. PARANÁ. Secretaria do Estado da Educação. Superintendência da Educação. Resolução 1.690 - 27 de Abril de 2011. Publicado no Diário Oficial nº 8472 de 24 de Maio de 2011.

PARO, V. H. et al. Escola de tempo integral: desafio para o ensino público. São Paulo: Cortez; São Paulo: Autores Associados, 1988.

REIS, Nadson Santana. O esporte educacional como tema da produção do conhecimento no periodismo cientifico brasileiro: uma revisão sistemática. Revista Pensar a Prática, Goiânia, v. 18, n. 3, jul./set. 2015.

SÉRGIO, Manuel. Algumas teses sobre o desporto. Lisboa: Compendium, 2003.

Recebido em: junho/2016 Aprovado em: março/2017 